\title{
A New Approach to the Diagnosis of Enzootic Leukosis by Genetic Markers of Bovine Leukemia Virus
}

\author{
Mariya E. Gorbunova ${ }^{1 \mathbb{D}}$, Regina F. Safina ${ }^{1 \mathbb{D}}$, Konstantin V. Usoltcev ${ }^{1 \mathbb{D}}$, Rafkat I. Shangaraev ${ }^{1(\mathbb{D})}$, \\ Marina A. Efimova ${ }^{1,2} \mathbb{D}$, Konstantin A. Osyanin ${ }^{1 \mathbb{D}}$, Tagir K. Faizov ${ }^{1 \mathbb{D}}$, Alina I. Khamidullina ${ }^{2} \mathbb{D}$, Nail \\ I. Khammadov 1,* (D) \\ 1 Federal Center for Toxicological, Radiation and Biological Safety, Nauchniy Gorodok-2, Kazan, 420075, Russian \\ Federation; vnivi@vnivi.ru; \\ 2 Kazan State Academy of Veterinary Medicine named after N.E. Bauman, Kazan, Russian Federation; \\ kgavm_baumana@mail.ru; \\ * Correspondence: nikhammadov@mail.ru;
}

Scopus Author ID 57193510940

Received: 2.06.2021; Revised: 10.07.2021; Accepted: 14.07.2021; Published: 16.08.2021

\begin{abstract}
In this paper, we consider the $g p 51$ and $p 24$ genes of the bovine leukemia virus (BLV) as "DNA-targets" for the detection of the BLV proviral DNA. We found that the gp51 and p24 genes of BLV are sufficiently specific to be used as marker sequences in PCR. The bioinformatic analysis of intraspecies specificity was conducted for each primer combination, and as a result, we found that they are complementary to most of the full-genome nucleotide sequences of BLV isolates displayed at NCBI online resources. We were able to show that the designed primer combinations possess high sensitivity, reaching 15 cells $/ \mu 1$ in both variants. Furthermore, we compared the PCR method with the suggested primer combinations against other laboratory diagnostic methods, namely BLV-AGID and ELISA. Regarding BLV detection, the PCR method with each primer combination applied to genes gp51 and p24 separately was more effective than both AGID and ELISA; it surpassed the former by $13.5 \%$ and $14.4 \%$, respectively, and the latter by $6.1 \%$ and $7.0 \%$, respectively. The simultaneous use of both primer combinations on a single amplified mixture showed the largest number of BLV-infected cows (53 animals) compared to the separate amplification of each genetic marker.
\end{abstract}

Keywords: bovine leukemia virus (BLV); polymerase chain reaction (PCR); genome; nucleotide; FLK-BLV; genotype.

(C) 2021 by the authors. This article is an open-access article distributed under the terms and conditions of the Creative Commons Attribution (CC BY) license (https://creativecommons.org/licenses/by/4.0/).

\section{Introduction}

Bovine leukemia virus (BLV) is a health problem of particular relevance for the whole world. It causes significant economic losses [1-9]. According to Rosselkhoznadzor data [10], 1602551 heads of cattle were examined by hematological sampling in 2020; 18521 animals tested positive to BLV, and 19764 had to be slaughtered. BLV causes blood and lymph disease in cattle. They are the natural host of BLV. At present, neither treatment nor vaccine has proven to be effective against BLV [11].

The virus integrates into B-lymphocytes, which implies a lifelong infection for the animal [12]. The greatest damage to breeding farms is caused by leukemia since the gene pool of breeds gets destroyed due to anti-epizootic measures. As a consequence of leukemia-related restrictions, breeding farms cannot sell genetically valuable bull calves and heifers, and they turn into commodity producers of meat and milk. BLV and human T-cell leukemia viruses type 
1 and type 2 (HTLV-1 and HTLV-2) are closely related representatives of the same family, Retroviridae, and both cause hematological diseases [13, 14]. Recently, BLV has been identified in human breast tissue and blood cells, and there are suggestions that it may be involved in developing breast cancer in women [15-19].

Diagnostic studies of leukemia in the Russian Federation rely on serological (agar-gel immunodiffusion (AGID) and enzyme-linked immunosorbent assay (ELISA)), molecular biological (PCR), hematological, clinical, and pathomorphological methods [20]. Currently, the system of preventive measures in the Russian Federation is based on the AGID assay. However, as practice shows, the currently employed diagnostic methods do not solve the problem of leukemia. They have been meticulously developed and possess many advantages but do not ensure the detection of all BLV-infected animals. A significant disadvantage of serological and hematological diagnostic methods is their inability to detect BLV in the early stages of the disease. PCR, on the contrary, makes possible the diagnosis of leukemia at any stage of development of the disease (after the insertion of a proviral insert into the animal genome), thereby avoiding time delays, which is crucial in this case. The method makes detecting infected animals among those testing seronegative (calves under six months old at early stages of infection) [21].

A 1991 paper by R. B. Brandon et al. is considered one of the first reports on using the PCR method to diagnose enzootic leukosis [22]. They successfully applied PCR with electrophoretic detection for the detection of BLV proviral DNA in experimentally infected sheep. In cattle, PCR for leukemia diagnosis was first used by M. P. Murtaugh et al. [23] in 1991. They examined blood from seropositive and seronegative cows and detected the pathogen in 13 out of 18 seropositive animals at different stages of infection. Rola \& Kuzmak [24] used a very interesting variation of the nested PCR assay to detect reaction products by the ELISA assay (PCR-ELISA). The sensitivity of the assay was $10^{-4} \mathrm{ng}$ of proviral DNA in a background of $1 \mu \mathrm{g}$ of BLV-negative host DNA, which significantly exceeded the electrophoretic detection and equaled the sensitivity of Southern blot hybridization.

Jaworski et al. [25] conducted an interlaboratory comparison of six quantitative or realtime PCR (qPCR) assays to detect the enzootic leukosis virus. All the assays were based on the identification of specific regions of the pol and tax genes. In the study, 58 DNA samples were distributed to and separately examined at research laboratories in Argentina, Belgium, Germany, Japan, Poland, and the United Kingdom, according to their respective qPCR protocols. Out of the 57 seropositive samples, 47, 45, 49, 32, 53, and 56 samples were positive by the Argentinian, Belgian, German, Japanese, Polish, and UK qPCR methods, respectively. The most sensitive method was the UK qPCR, and the method with the lowest sensitivity was the Japanese qPCR. Moreover, 33 of the 58 samples were correctly identified by all qPCR methods. A single BLV-seropositive sample (№ 31) tested negative by all qPCR assays. The remaining 24 samples gave inconsistent results. A comparison of the qualitative results (positive versus negative) from all six laboratories yielded an $80 \%$ overall agreement and a kappa value of 0.342 (Cohen's kappa method adapted by Fleiss). The highest agreement was observed between two laboratories: the Polish and the UK, with $94.8 \%$ agreement and a Cohen's kappa value of 0.549 . These two laboratories used similar protocols and targeted the same region of the BLV pol gene.

Jimba et al. [26] designed degenerate primers from 52 individual BLV long-terminal repeat (LTR) sequences identified from 356 BLV sequences in GenBank using the CoCoMo algorithm, specifically developed for the detection of several virus species. By melting-curve 
analysis after real-time PCR amplification, the most specific primers for detecting BLV LTR were selected from 72 sets of primers out of 49 candidate primers. An internal BLV TaqMan probe was used to enhance the specificity and sensitivity of the assay. The assay was highly specific, sensitive, quantitative, and reproducible; it detected BLV in several samples that tested negative by previously developed nested PCR assays.

According to data available in the literature on the use of PCR in the diagnosis of bovine leukosis, we can draw the following conclusions:

1. A rather large number of PCR assays have been developed for BLV detection ("classical" PCR, nested PCR, PCR-ELISA, real-time PCR, BLV-CoCoMo-qPCR, and so forth).

2. Each PCR assay has advantages and disadvantages.

3. Most PCR methods are based on the determination of a single gene that is represented in the genome of the pathogen, usually by one copy (e.g., p24, gp51, pol, gag, tax, env), except for the long-terminal repeat (LTR) sequence, which is represented by two copies.

Firstly, single-target PCR assays can have reduced sensitivity since only one copy of the gene is detected (except for LTR) [27-28]. Secondly, mutations in the pathogen genome, especially in regions where primers and probes bind to the template DNA, can lead to falsenegative PCR results and reduce the assay specificity [29].

In this paper, we consider using various "genetic" targets for the detection of BLV proviral DNA, both separately and in combinations, to overcome the reduction of the sensitivity and specificity of assays.

\section{Materials and Methods}

\subsection{Samples.}

Blood and blood serum samples were collected from adult cattle at several agricultural enterprises of the Republic of Tatarstan. Samples were not frozen. Additionally, we used a culture of fetal lamb kidney (FLK) cells chronically infected with BLV in the experiments. Blood samples, blood serum, and the FLK culture were stored at a temperature of $2{ }^{\circ} \mathrm{C}$ to $8{ }^{\circ} \mathrm{C}$ for no more than 3 days before DNA extraction.

\subsection{DNA extraction.}

The "DNA-sorb B" kit (Rospotrebnadzor Central Research Institute of Epidemiology) was used for the extraction of nucleic acids. The DNA was extracted as per the manufacturer's instructions. The amount of extracted DNA was determined using a UV5Nano spectrophotometer (Mettler Toledo). The DNA concentration of the samples ranged from 18 to $30 \mathrm{ng} / \mathrm{ml}$.

\subsection{ELISA.}

For ELISA, we used a kit for the detection of BLV antibodies (Vetbiokhim, Moscow).

2.4. AGID.

For AGID, we used a kit for serological diagnosis of bovine leukosis (FKP "Kurskaia biofabrika-Firma "Biok"”, Kursk). 


\subsection{Nested PCR.}

As a validation procedure for the developed PCR methods for detection of BLV proviral DNA, we used a modification of nested PCR with "external" ("env 5032"-5'tctgtgccaagtctcccagata-3' and "env 5608"-5'-aacaacaacctctgggaagggt-3) and "internal" ("env 5099"-5'-cccacaagggcggcgccggttt-3' and "env 5521"-5'-gcgaggccgggtccagagctgg-3') primers, initiating the amplification of a fragment of the BLV gene env of 444 base pairs in length, according to Beier [30].

\subsection{Design and synthesis of primers and fluorescently labeled probes.}

We used the complete genome sequence of the BLV (GenBank ID: K02120.1) [31]. In the design of primers and the oligonucleotide probe specific to the nucleotide sequences of the BLV gp51 gene, we made use of the Vector NTI 9.1 software package. A previously published paper described the design of primers and fluorescently labeled probes specific to the BLV p24 gene [32]. Primers and fluorescent probes for real-time PCR were synthesized by Sintol LLC (Moscow, Russia).

\subsection{Bioinformatic analysis.}

We examined the intraspecies specificity of the designed primers and probes with respect to several isolates of BLV. For this, we performed a multiple alignment of 80 fullgenome sequences of BLV (AF033818, AF257515 [33], LC433846 [34], LC436098 [34], EF600696 [35], AB934283, AB934282, HE967301, HE967302, HE967303, LC005616, LC005615, AP018007 [36], AP018008 [36], AP018009 [36], AP018010 [36], AP018012 [36], AP018013 [36], AP018014 [36], AP018015 [36], AP018016 [36], AP018017 [36], AP018018 [36], AP018019 [36], AP018020 [36], AP018021 [36], AP018022 [36], AP018023 [36], AP018024 [36], AP018025 [36], AP018026 [36], AP018027 [36], AP018028 [36], AP018029 [36], AP018030 [36], AP018031 [36], AP018032 [36], AP018006 [36], MG800834 [37], MH170028 [38], MH170029 [38], MH170030 [38], MH170027 [38], KT122858, K02120 [31], LC080651 [39], LC080652 [39], LC154848 [40], LC080654 [39], LC080659 [39], LC080660 [39], LC080661 [39], LC080662 [39], LC080663 [39], LC080653 [39], LC080655 [39], LC080656 [39], LC080657 [39], LC080658 [39], LC080664 [39], LC080665 [39], LC080666 [39], LC080667 [39], LC080668 [39], LC080669 [39], LC080670 [39], LC080671 [39], LC080672 [39], LC080673 [39], LC080674 [39], LC080675 [39], LC154849 [39], FJ914764 [41], MF580991 [42], MF580993 [42], MF580994 [42], MF580992 [42], MF580995 [42], MF580990 [42], NC_001414) stored in the nucleotide sequence database at the National Center for Biotechnology Information (NCBI). For the analysis, we employed the program AlignX from the Vector NTI 9.1 software package.

\subsection{Positive control sample.}

As the positive control sample (PCS) in the contrived methods for real-time PCR, we used a preparation of DNA extracted from a culture of fetal lamb kidney cells chronically infected with BLV (FLK-BLV). 


\subsection{Real-time polymerase chain reaction.}

The amplification was performed on a DT 96 detecting amplifier (DNA-Technologia, Russia) and a C1000 thermal cycler chassis with a CFX96 optical reaction module (Bio-Rad, USA), in test tubes of $0.2 \mathrm{~cm}^{3}$.

The detection of the BLV p24 gene by real-time PCR was performed according to the following amplification protocol: (phase I) DNA denaturation at $95{ }^{\circ} \mathrm{C}$ for 5 minutes; (phase II) 42 cycles at $95{ }^{\circ} \mathrm{C}$ for 15 seconds and $61^{\circ} \mathrm{C}$ for 30 seconds (detection through the ROX channel); (phase III) preservation at $10{ }^{\circ} \mathrm{C}$.

The detection of the BLV gp51 gene by real-time PCR was performed according to the following amplification protocol: (phase I) DNA denaturation at $95{ }^{\circ} \mathrm{C}$ for 5 minutes; (phase II) 42 cycles at $95{ }^{\circ} \mathrm{C}$ for 15 seconds and $60{ }^{\circ} \mathrm{C}$ for 30 seconds (detection through the ROX channel); (phase III) preservation at $10{ }^{\circ} \mathrm{C}$.

The simultaneous detection of the $g p 51$ and $p 24$ genes by real-time PCR was performed according to the following amplification protocol: (phase I) DNA denaturation at $95{ }^{\circ} \mathrm{C}$ for 5 minutes; (phase II) 42 cycles at $95{ }^{\circ} \mathrm{C}$ for 15 seconds and $60.5^{\circ} \mathrm{C}$ for 30 seconds (detection through the ROX channel); (phase III) preservation at $10{ }^{\circ} \mathrm{C}$.

The composition of the PCR mixture for detection of the gp51 and p24 genes was as follows: $1.5 \mu \mathrm{l}$ of 10-fold PCR buffer (Sintol LLC, Russia); $1.5 \mu \mathrm{l}$ of $2.5 \mathrm{mM}$ dNTP solution (Sintol LLC, Russia); $1.5 \mu \mathrm{l}$ of $25 \mathrm{mM} \mathrm{MgCl}_{2}$ solution (Sintol LLC, Russia); $10 \mathrm{pM}$ solutions of primers and fluorescently labeled probes specific to the BLV gp51 and p24 genes $(0.5 \mu \mathrm{l}$ of each oligonucleotide); $0.5 \mu \mathrm{l}$ of Taq polymerase (5 units/ $\mu$ l) (Sintol LLC, Russia); 5.5 to $7 \mu \mathrm{l}$ of the test sample (template DNA). Specific oligonucleotides (primers and probes) were synthesized by Sintol LLC (Russia). The final volume of the reaction mixture was $15 \mu 1$.

\section{Results and Discussion}

\subsection{Search for unique nucleotide sequences.}

We used the NCBI nucleotide sequence databases to search for unique and specific nucleotide sequences for the detection of BLV proviral DNA. The corresponding search query was built on the following keywords: bovine leukemia virus, BLV. The search yielded 2731 nucleotide sequences of BLV genes. In the obtained data set, we found a full-genome sequence of BLV, K02120.1, which we used for further research and the design of primer combinations. It is worth noting that we chose the K02120.1 nucleotide sequence because the main BLV genes, including $p 24$ and $g p 51$, which we used for further processing, are clearly rendered in it.

Next, we searched for the most specific regions of the BLV genome. The gp51 and p24 genes were chosen. The $g p 51$ gene is part of the env gene and encodes the surface protein gp51, which, together with the transmembrane protein gp30, interacts with the virus and the cell [44]. The $p 24$ gene is part of the gag gene and encodes the BLV nucleocapsid protein p24. Thus, considering the functional characteristics of the proteins that encode the relevant genes (i.e., gp51 and p24), we conclude that the genes used to design primer combinations for real-time PCR must have sufficient specificity. 
The nucleotide sequences of the $g p 51$ and $p 24$ genes were then copied from the BLV full-genome sequence and saved as a separate file in the *.gb format, using the program Vector NTI 9.1.

Afterward, we used the sequences of these genes to design primers and fluorescent probes to detect BLV proviral DNA.

\subsection{Design of specific primers and an oligonucleotide probe to specific BLV sequences.}

For the design of primers and an oligonucleotide probe that are specific to the nucleotide sequence of the gp51 gene, we used the Vector NTI 9.1 program. As a previous step, we copied the target sequences of these genes from the NCBI site, saved them in the GenBank format (*.gb), and loaded them into Vector NTI 9.1 (see Figure 1).

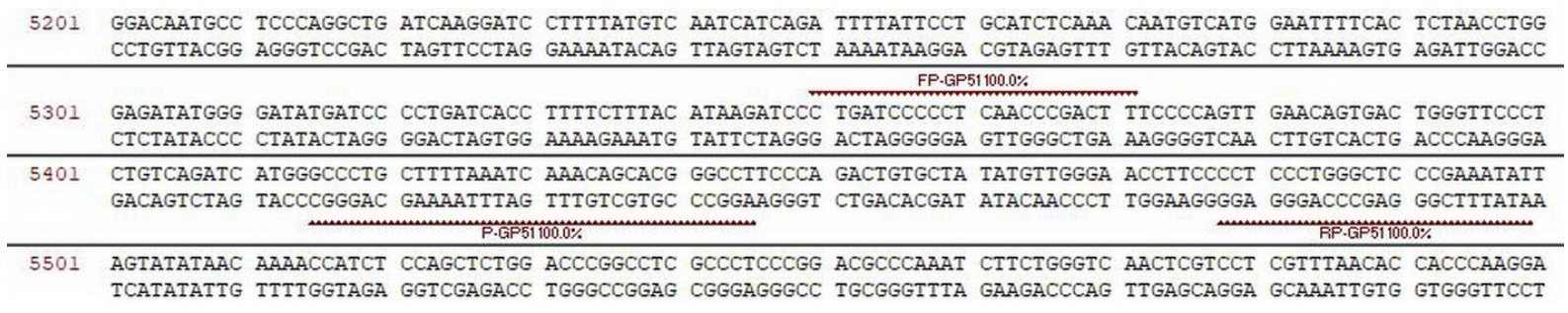

Figure 1. The nucleotide sequence of a part of the glycoprotein gene $g p 51$, indicating the binding sites for specific primers and probes (Vector NTI 9.1 interface is shown in the figure). FP, RP, and Z denote the binding site of the forward primer, the reverse primer, and the oligonucleotide probe, respectively.

A previously published paper described the design of primers and fluorescently labeled probes for the BLV p24 gene [32].

In Table 1, we can see the primers and oligonucleotide probes, grouped in primer combinations designed to detect the BLV proviral DNA.

\begin{tabular}{|c|c|c|c|}
\hline Function & $\begin{array}{c}\text { Position in the } \\
\text { nucleotide } \\
\text { sequence }\end{array}$ & $\begin{array}{c}\text { Primer } \\
\text { combination }\end{array}$ & Nucleotide sequence $5^{\prime} \rightarrow 3^{\prime}$ \\
\hline Forward primer & $5350-5371$ & \multirow{3}{*}{$\begin{array}{c}\text { Primer } \\
\text { combination I } \\
\text { specific to the } \\
\text { gp51 gene }\end{array}$} & ctgatcccctcaaccegactt \\
\hline Reverse primer & $5478-5499$ & & atatttcgggagcccagggagg \\
\hline Oligonucleotide probe & $5415-5445$ & & $\begin{array}{c}\text { FAM-aggcccgtgctgtttgatttaaaagcagggc- } \\
\text { BHQ1 }\end{array}$ \\
\hline Forward primer & $1041-1061$ & \multirow{3}{*}{$\begin{array}{c}\text { Primer } \\
\text { combination II } \\
\text { specific to the } p 24 \\
\text { gene }\end{array}$} & ggcaccgggttcgcaagtatg \\
\hline Reverse primer & $1159-1180$ & & ccgttaggctggtcatgtgggc \\
\hline Oligonucleotide probe & $1126-1154$ & & $\begin{array}{c}\text { ROX-tgatcgaccggggaagcaatatattggca- } \\
\text { BHQ2 }\end{array}$ \\
\hline
\end{tabular}

Note: Oligonucleotides were designed taking as a basis the nucleotide sequence K02120.1 (GenBank ID).

\subsection{In silico assessment of the intraspecies specificity of the BLV p24 and gp51 genes.}

Another important criterion in the design of oligonucleotides for real-time PCR is the analysis of the selected sequences in terms of their degree of genetic diversity, particularly to what extent primers and probes for detecting certain virus isolates are suitable for other BLV isolates. For this reason, we decided to research how the sequences of the genes gp51 and p24 in different virus isolates differ from each other. For this purpose, we searched for "bovine leukemia virus" in the NCBI database of nucleotide sequences and found 80 full-genome sequences of BLV (they are indicated in the "Materials and Methods" section). Then, we examined the sequences with the program AlignX from the Vector NTI 9.1 package. In particular, we conducted multiple alignments of nucleotide sequences to assess the degree of conservation of the primers and oligonucleotide probes (see Table 1) that we designed to detect 
BLV proviral DNA by real-time PCR. We began with the analysis of the combination of primers flanking the region of the BLV gp51 gene (FP-GP51, RP-GP51, and P-GP51).

The forward primer FP-GP51 is complementary to nucleotides 5367-5388 in the BLV full-genome nucleotide sequence $\mathrm{AB} 934282$. It is not found in the nucleotide sequences AB934283 and LC433846. Furthermore, in the DNA segment complementary to the FP-GP51 primer, there are single-point substitutions in the nucleotide sequences MH170027, MH170030, LC154849, MF580994, and MF580995. In the remaining 74 BLV nucleotide sequences considered, the FP-GP51 primer fully complements the target BLV DNA region, which indicates a sufficient degree of conservation of this DNA segment.

The reverse primer RP-GP51 is complementary to nucleotides 5367-5388 in the BLV full-genome nucleotide sequence $\mathrm{AB} 934282$. It is absent from the nucleotide sequence AB934283. Furthermore, in the DNA segment complementary to this primer, there are singlepoint substitutions inside the nucleotide sequences LC154849 and MF580993. In the remaining 78 BLV sequences provided, the RP-GP51 primer fully complements the specified BLV DNA region.

The oligonucleotide probe P-GP51 is complementary to nucleotides 5432-5456 in the BLV full-genome nucleotide sequence AB934282. It is absent from the nucleotide sequences AB934283 and LC433846. This probe is fully (100\%) complementary to the DNA regions in 34 of the sequences (AP018008, AP018015, AP018032, HE967301, HE967302, HE967303, LC080653, LC080651, LC080652, AP018029, AP018030, LC436098, AP018020, BLVCG, AP018022, AP018023, AP018031, AP018021, AP018007, AP018012, AP018016, AP018018, AP018015, AP018027, LC005616, LC005615, MH170028, MH170027, AP018026, AP018028, AP018024, AP018014, AP018019, AP018009, AB934282). In the remaining sequences, point nucleotide substitutions occur in the BLV DNA sections complementary to the probe P-GP51. It should also be noted that two or three nucleotide substitutions are found in the regions complementary to this probe in 14 nucleotide sequences (LC080657, LC080658, MF580992, AF257515, FJ914764, LC080655, MG800834, LC154848, MF580993, LC154849, MF580994, MF580995, LC080654, EF600696).

Next, we examined the combination of primers flanking the region of the BLV p24 gene. The forward primer FP-P24 is complementary to nucleotides 1047-1067 in the sequence $\mathrm{AB} 934282$. In 53 of the sequences, this primer is fully complementary to the sought DNA regions. In 28 sequences (AP018014, LC080656, MF580990, LC154848, MF580993, LC080659, LC080663, LC080662, LC080661, LC080664, LC080670, LC080665 LC080667, LC080669, LC080673, LC080671, LC080674, LC080675, LC080666, LC080668, LC080672, LC080660, HE967301, HE967302, HE967303, LC080653, LC080652, AP018027), there are point nucleotide substitutions in the DNA region to which the primer FP-P24 is complementary. Furthermore, 17 nucleotide sequences (LC080659, LC080663, LC080662, LC080661, LC080664, LC080670, LC080665, LC080667, LC080669, LC080673, LC080671, LC080674, LC080675, LC080666, LC080668, LC080672, LC080660) have two or three point nucleotide substitutions in the region complementary to the primer.

The reverse primer RP-P24 is complementary to the region of the nucleotide sequence AB934282 at positions 1165-1186. In 45 sequences, this primer is fully complementary to the specified DNA regions. In 36 nucleotide sequences (AF033818, NC_001414, KT122858, LC080656, MF580990, MH170029, MH170030, LC080657, LC080658, MF580991, MF580992, LC154848, MF580993, LC154849, MF580994, MF580995, AF257515, FJ914764, LC080655, LC080654, LC080659, LC080663, LC080662, LC080661, LC080664, 
LC080670, LC080665, LC080667, LC080669, LC080673, LC080671, LC080675, LC080666, LC080668, LC080672, LC080660), there are point nucleotide substitutions in the DNA region to which the primer RP-P24 is complementary. There are 5 nucleotide sequences (MF580990, MF580992, AF257515, FJ914764, LC080655) having 2 point nucleotide substitutions in the region complementary to the primer.

The oligonucleotide probe P-P24 is complementary to the nucleotide sequence AB934282 at positions 1132-1156. In 79 of the sequences, the probe is fully complementary to the indicated DNA regions. In 2 sequences (AP018007 and MF580993), there are point nucleotide substitutions at the indicated sites. The small number of nucleotide sequences with mutations suggests that the probe is complementary to a fairly conservative section of the BLV genome.

Summing up the bioinformatic analysis of the BLV full-genome nucleotide sequences found in the NCBI database, we can affirm that the designed primer combinations for the BLV gp51 and p24 genes flank rather conservative regions of the pathogen's genome, in particular, the primers and the probe specific to the gene of the virus nucleocapsid protein $\mathrm{p} 24$. The point nucleotide substitutions that occur in some sequences are, in most cases, single and are located roughly in the middle of the DNA region complementary to the primer or probe. Ultimately, this does not have a significant impact on the PCR results. The conservation of the flanked regions of the genome is a rather convenient feature when developing a universal real-time PCR method capable of detecting most of the known BLV isolates. However, in the DNA regions complementary to the primer combination specific to the BLV gp51 gene, 14 BLV fullgenome nucleotide sequences have two or three-point nucleotide substitutions each. As for the primers specific to the BLV p24 gene, there are already 22 nucleotide sequences with two or three-point nucleotide substitutions. Incomplete complementarity and point substitutions at the ends of the "annealing" of primers can eventually lead to difficulties with PCR tests [26, 44].

Also, the AB934283 and LC433846 sequences do not contain any complementary regions whatsoever for the primer combination specific to the gp51 gene. This means that PCR is impossible for the said sequences with the said combination of primers. To overcome the possible difficulties with PCR, we suggest the simultaneous use of two primer combinations specific to the $p 24$ and $g p 51$ genes in a single PCR reaction mixture to detect the BLV proviral DNA. This approach makes it possible to identify most known types and isolates of BLV, including the mutant forms thereof. Furthermore, the simultaneous use of two loci of the BLV proviral DNA as "targets" in PCR significantly increases the chances of detecting the BLV pathogen in the studied samples, regardless of its genetic diversity.

\subsection{Assessment of the sensitivity of the designed primer combinations.}

Sensitivity is one of the main quality indicators of laboratory methods for detecting pathogens of infectious diseases. This indicator shows which minimum amount of wanted "target" substance in a given volume the method can determine. It depends on many factors but, first of all, on the quality of the process of extraction of nucleic acid from the primary material, the correct choice of temperature and time conditions, the components of the reaction mixture, and the accuracy of the selection of primers and fluorescent oligonucleotide probes. Below, we set forth the results obtained when assessing the sensitivity of the real-time PCR method by previously designed primer combinations.

To assess the sensitivity of the PCR method, we prepared a series of ten-fold dilutions from a suspension of a culture of FLK-BLC cells. The obtained DNA concentration ranged 
from $1.5 \times 10^{6}$ to $1.0 \times 10^{0}$ cells $/ \mu$ l. The cells were counted as per the standard procedure using a hemocytometer. In real-time PCR with a primer combination specific to the BLV gp51 gene, the minimum dilution of FLK-BLV cells at which we could record a positive signal was $1,5 \times 10^{1}$ cells $/ \mu$ l (see Table 2 and Figure 2 ). The same sensitivity $\left(1,5 \times 10^{1}\right.$ cells $/ \mu 1$ ) was obtained when using a primer combination specific to the BLV p24 gene (see Table 2 and Figure 3).

Table 2. Sensitivity of the PCR method with the designed primer combinations.

\begin{tabular}{|c|c|c|c|}
\hline Test tube descriptor & $\begin{array}{c}\text { Quantification limit } \\
\quad(\text { cells } / \mu \mathrm{l})\end{array}$ & $\begin{array}{l}\text { Primer combination I specific } \\
\text { to the BLV gp51 gene } \\
\text { Ct (ROX) (cycles) }\end{array}$ & $\begin{array}{l}\text { Primer combination II } \\
\text { specific to the BLV p24 } \\
\text { gene } \\
\text { Ct (ROX) (cycles) }\end{array}$ \\
\hline Negative control sample & & unspec. & unspec. \\
\hline $1^{\text {st }}$ dilution $\left(10^{0}\right)$ & $1.5 \times 10^{6}$ & 18.34 & 18.08 \\
\hline $2^{\text {nd }}$ dilution $\left(10^{-1}\right)$ & $1.4 \times 10^{5}$ & 21.77 & 21.87 \\
\hline $3^{\text {rd }}$ dilution $\left(10^{-2}\right)$ & $1.2 \times 10^{4}$ & 25.10 & 24.68 \\
\hline $4^{\text {th }}$ dilution $\left(10^{-3}\right)$ & $1.5 \times 10^{3}$ & 28.31 & 28.69 \\
\hline $5^{\text {th }}$ dilution $\left(10^{-4}\right)$ & $1.3 \times 10^{2}$ & 31.08 & 31.67 \\
\hline $6^{\text {th }}$ dilution $\left(10^{-5}\right)$ & $1.5 \times 10^{1}$ & 33.71 & 33.61 \\
\hline $7^{\text {th }}$ dilution $\left(10^{-6}\right)$ & $1.0 \times 10^{0}$ & unspec. & unspec. \\
\hline
\end{tabular}

Note: unspec.-unspecified; Ct-threshold cycle.

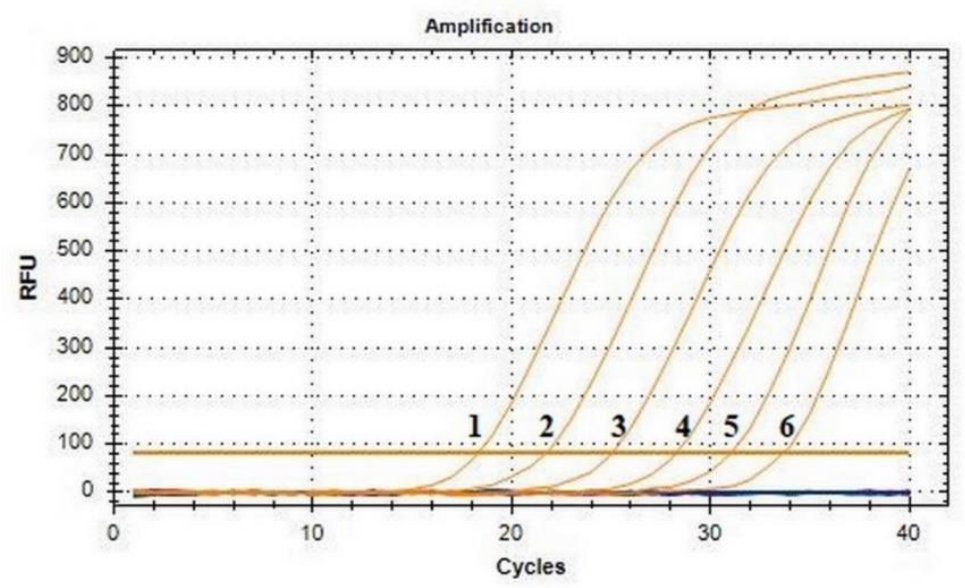

Figure 2. Sensitivity assessment of the PCR method based on the detection of the BLV gp51-gene region (the figure shows the interface of CFX Manager 3.1 (Bio-Rad, USA)). Notations: Graphs 1, 2, 3, 4, 5 , and 6 show the fluorescence to DNA extracted from 10-fold dilutions of the positive control sample (FLK-BLV cell culture).

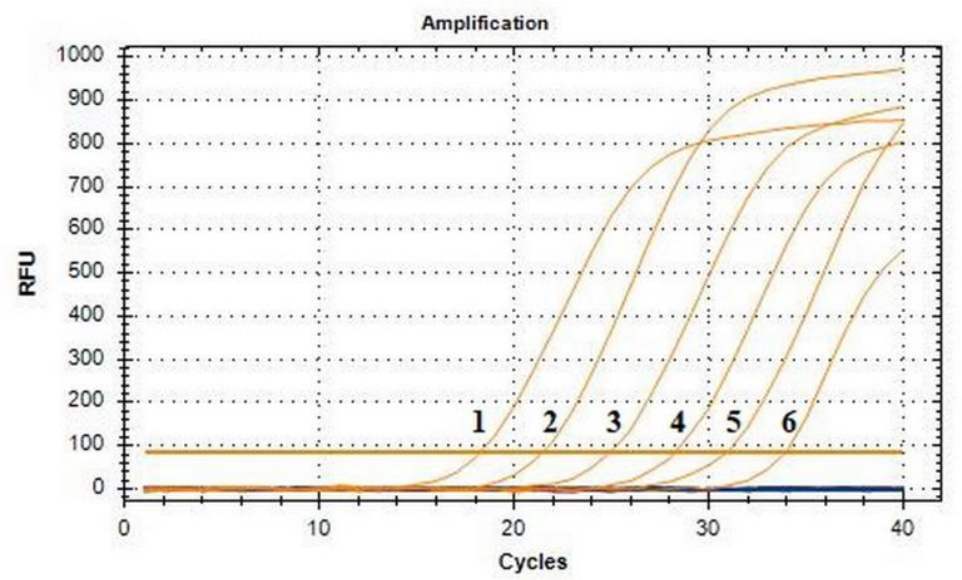

Figure 3. Sensitivity assessment of the PCR method based on the detection of the BLV p24-gene region (the figure shows the interface of CFX Manager 3.1). Notations: Graphs 1, 2, 3, 4, 5, and 6 show the fluorescence to DNA extracted from 10-fold dilutions of the positive control sample (FLK-BLV cell culture). 
3.5. Assessment of the specificity of the designed primer combinations for PCR-based detection of $B L V$.

For assessing the specificity of the developed methods, we used the following DNA samples: DNA extracted from a virus-producing culture of fetal lamb kidney cells (FLK-BLV); DNA extracted from the blood of a healthy cow; DNA extracted from a cell culture infected with herpesvirus (the pathogen of bovine infectious rhinotracheitis); cDNA of rabies virus; DNA extracted from a culture of E. coli; DNA extracted from a culture of Salmonella typhimurium; DNA extracted from a Bacillus subtilis culture; DNA extracted from a culture of Staphylococcus aureus; DNA extracted from the blood of a healthy lamb; DNA extracted from rabbit blood. The results are given in Table 3 and Figure 4.

Table 3. Specificity of the primer combinations for the BLV gp51 and p24 genes. Probe descriptor

$\mathrm{K}-$ (deionized water)

BLV proviral DNA. extracted from a culture of fetal lamb kidney cells chronically infected with BLV (FLK-BLV)

DNA extracted from healthy cow blood

cDNA of rabies virus

DNA isolated from a culture of cells infected with herpesvirus

(the pathogen of bovine infectious rhinotracheitis)

DNA extracted from a culture of $E$. coli

DNA extracted from a culture of Salmonella typhimurium

DNA extracted from a culture of Bacillus subtilis

DNA extracted from a culture of Staphylococcus aureus

DNA extracted from healthy lamb blood

DNA extracted from rabbit blood

Note: unspec.---unspecified; Ct---threshold cycle.

\begin{tabular}{|c|c}
$\begin{array}{l}\text { Primer combination I } \\
\text { specific to the BLV gp51 } \\
\text { gene } \\
\text { Ct (ROX) (cycles) }\end{array}$ & $\begin{array}{l}\text { Primer combination II } \\
\text { specific to the BLV p24 gene } \\
\text { Ct (ROX) (cycles) }\end{array}$ \\
\hline unspec. & unspec. \\
\hline 19.82 & 20.43 \\
\hline unspec. & unspec. \\
\hline unspec. & unspec. \\
\hline unspec. & unspec. \\
\hline unspec. & unspec. \\
\hline unspec. & unspec. \\
\hline unspec. & unspec. \\
\hline unspec. & unspec. \\
\hline unspec. & unspec. \\
\hline unspec. & unspec. \\
\hline
\end{tabular}

Amplification

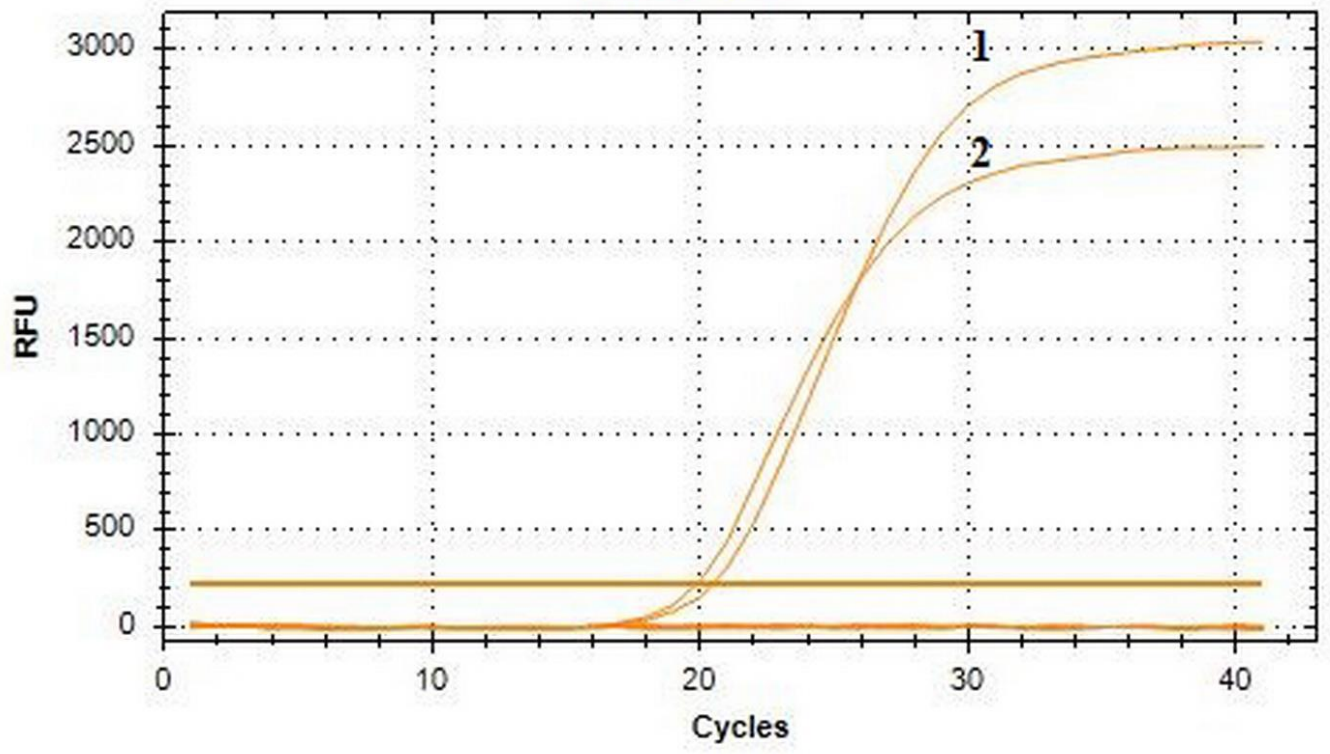

Figure 4. The test results for the specificity of primer combinations designed for the BLV gp51 and $p 24$ genes (the figure shows CFX Manager 2.1 interface). Notations: Graphs 1 and 2 show the fluorescence vs. the number of cycles for primer combinations specific to the p24 (1) and gp5l (2) genes of the BLV genome in FLK-BLV

DNA.

The data presented (Table 3, Figure 4) shows that the combinations of primers for the BLV gp51 and p24 genes, designed to detect proviral BLV DNA by PCR, are highly specific. 
These combinations detect only the BLV proviral DNA. All heterologous DNA samples tested negative.

3.6. Assessment of the effectiveness of the primer combinations designed to detect BLV proviral DNA, compared to ELISA and AGID assays.

In this study, we used primer combinations for the gp51 and p24 genes of the BLV genome. We assessed the effectiveness of these primer combinations in real-time PCR against the results yielded by generally accepted laboratory assays for diagnosing bovine leukosis (e.g., AGID and ELISA). For this, we examined blood and serum samples from 325 cows collected at several farms of the Republic of Tatarstan (Russian Federation). In the study, we used nested PCR (modified by Beier [30]) as a standard method for determining BLV proviral DNA. The presence of BLV proviral DNA was found in 215 blood samples, that is, $66.15 \%$ of the total number of animals investigated. In blood sera from the same animals, we detected the presence of BLV-specific antibodies in 196 samples using ELISA (that is, 91.1\% relative to nested PCR) and 180 samples using AGID (83.7\% relative to nested PCR) (Table 4).

Table 4. Results of the analysis of samples by the designed primer combinations, nested PCR, ELISA, and AGID.

\begin{tabular}{l|c|c|c|c|c} 
& Nested PCR & $\begin{array}{l}\text { Primer combination } \\
\text { for detection of the } \\
\text { BLV gp51 gene }\end{array}$ & $\begin{array}{l}\text { Primer combination } \\
\text { for detection of the } \\
\text { BLV p24 gene }\end{array}$ & ELISA & AGID \\
\hline Total number of samples & 325 & 325 & 325 & 325 & 325 \\
\hline Number of positive tests & 215 & 209 & 211 & 196 & 180 \\
\hline $\begin{array}{l}\text { Sensitivity \% relative to } \\
\text { nested PCR }\end{array}$ & & 97.2 & 98.1 & 91.1 & 83.7
\end{tabular}

According to our data, in the study of 325 blood samples, the sensitivity of the primer combinations specific to the BLV gp51 and p24 genes was $97.2 \%$ and $98.1 \%$, respectively, relative to the number of samples that tested positive by the nested PCR method.

In the AGID assay, 35 samples out of 215 tested negative for BLV, so the sensitivity of the AGID method was $83.7 \%$.

19 samples tested negative in the ELISA assay, so the method's sensitivity was $91.1 \%$ of the number of positive samples. Comparing the results, we concluded that the designed primer combinations for the gp51 and p24 genes are more effective for detecting the pathogen of bovine leukosis than both AGID by $13.5 \%$ and $14.4 \%$, respectively, and ELISA by $6.1 \%$ and $7.0 \%$, respectively.

\subsection{Real-time PCR test of the primer combinations for detection of BLV proviral DNA.}

In this study, we tested two primer combinations: a combination I for detection of the gp51 gene region of the BLV genome, and combination II, for detection of the $p 24$ gene region of the BLV genome. We also tested a third primer combination, designed as a mixture of primer combinations I and II, for simultaneous detection of the gp51 and p24 regions of the BLV genome. The third combination was introduced to determine whether it is possible to increase the sensitivity of the real-time PCR method by simultaneously using primer combinations specific to different "DNA targets" in one PCR mixture.

We examined 102 blood samples from cows owned by "Kamsko-Ustinskoe" LLC, a farm located in Kamsko-Ustinsky district (Republic of Tatarstan, Russian Federation). The results are shown in Table 5. 
Table 5. Real-time PCR test of blood samples from cows owned by “Kamsko-Ustinskoe" LLC (KamskoUstinsky district, Republic of Tatarstan, Russian Federation).

\begin{tabular}{l|c|c|c} 
& $\begin{array}{l}\text { Primer combination I } \\
\text { (for detection of the } \\
\text { BLV gp51 gene) }\end{array}$ & $\begin{array}{l}\text { Primer combination II } \\
\text { (for detection of the } \\
\text { BLV p24 gene) }\end{array}$ & $\begin{array}{l}\text { Primer combination III } \\
\text { (for simultaneous } \\
\text { detection of BLV gp51 } \\
\text { and } \boldsymbol{p 2 4} \text { genes) }\end{array}$ \\
\hline Total number of samples & 102 & 102 & 102 \\
\hline Number of positive tests & 46 & 47 & 53 \\
\hline$\%$ of positive tests & 45.09 & 46.07 & 51.9 \\
\hline Mean Ct value (cycles) & 28.70 & 29.56 & 29.61
\end{tabular}

In the tests using primer combination I, designed to detect the BLV gp51 gene, the BLV proviral DNA was detected in 46 blood samples (45.09\% of the total number). When using primer combination II to detect the BLV p24 gene, the proviral DNA was detected in 47 blood samples $(46.07 \%$ of the total number).

The largest number of real-time PCR positive tests (53 samples, i.e., 51.9\% of the total number) was obtained with primer combination III. This combination, in which primers and fluorescently labeled probes, designed to detect different "DNA targets" (BLV gp51 and p24 genes) in a single PCR mixture, are used simultaneously, exceeded by 7 (6.86\%) and $6(5.88 \%)$, respectively, the numbers of positive tests yielded by combinations I and II.

Most likely, the larger number of positive tests produced by combination III, compared to primer combinations I and II separately, is because several BLV isolates circulate among the farm animals. As shown by the bioinformatic analysis of intraspecies specificity, some isolates can be detected by all primer combinations, whereas variants can be detected by only one combination of primers. This phenomenon can be explained by the presence of point mutations of the template DNA at the "annealing" points of specific primers and probes, and this can sometimes preclude PCR with certain primer combinations. In other words, when we use both primer combinations simultaneously in the PCR mixture, we increase the probability of detecting the BLV proviral DNA since each primer combination can detect its own specific set of isolates, which differs from that of other combinations. Thus, the simultaneous use of two or three sets of primers increases the number of detectable isolates. However, we should not forget that it is necessary to consider the interplay of primers and probes with each other to minimize the formation of dimers and concurrent interaction.

\section{Conclusions}

After conducting a bioinformatic analysis involving multiple alignments of fullgenome nucleotide sequences of BLV isolates stored in the NCBI database, we concluded that previously designed primer combinations complemented the gp51 and p24 gene regions are suitable for detection of the proviral DNA of most BLV isolates by real-time PCR. However, sequences also feature considerable point nucleotide substitutions at the "annealing" points of primers and probes, which can give rise to difficulties in PCR assays.

The simultaneous use of primer combinations designed for the BLV gp51 and p24 genes made it possible to detect a larger number of cows infected with leukosis in the studied herd.

Based on the found marker sequences (regions of the BLV gp51 and p24 genes), we developed an assay for diagnosing BLV by real-time PCR. Furthermore, we proved that the suggested method for detecting BLV proviral DNA is highly specific and sensitive. For this reason, it could become an effective tool for the early diagnosis of enzootic leukosis in 
conjunction with other methods, such as AGID and ELISA. This could speed up and make more effective the diagnostic measures taken to identify infected animals.

\section{Funding}

This research received no external funding

\section{Acknowledgments}

The research was carried out with the support of the Federal Center for Toxicological, Radiation, and Biological Safety.

\section{Conflicts of Interest}

The authors declare no conflict of interest.

\section{References}

1. John, E.E.; Keefe, G.; Cameron, M.; Stryhn, H.; McClure, J.T. Development and implementation of a risk assessment and management program for enzootic bovine leukosis in Atlantic Canada. Journal of Dairy Science 2020, 103, 8398-8406, https://doi.org/10.3168/jds.2019-17434.

2. Selim, A.; Megahed, A.A.; Kandeel, S.; Abdelhady, A. Risk factor analysis of bovine leukemia virus infection in dairy cattle in Egypt. Comparative Immunology, Microbiology and Infectious Diseases 2020, 72, 101517, https://doi.org/10.1016/j.cimid.2020.101517.

3. Bai, L.; Hirose, T.; Ass, W.; Wada, S.; Takeshima, S.N.; Aida, Y. Bovine leukemia virus infection affects host gene expression associated with DNA mismatch repair. Pathogens 2020, 9, 1-18, https://doi.org/10.3390/pathogens9110909.

4. Dogan, F.; Bilge Dagalp, S.; Dik, B.; Farzani, T.A.; Alkan, F. Detection of genotype 1 bovine leukemia virus from a C.schultzei pool: Do Culicoides spp. have a role on the transmission of bovine leukemia virus? Infection, Genetics and Evolution 2020, 85, 104469, https://doi.org/10.1016/j.meegid.2020.104469.

5. Honorio, T.C.D.D.; Oliveira Neto, J.R.D.; Oliveira, F.N.M.; Salazar, V.C.R.; Cruz, A.D.C.; Cunha, L.C.D. Occupational exposure evaluation of Brazil university community to the volatile organic compounds. Journal of Pharmaceutical and Biomedical Analysis 2020, 191, 113637, https://doi.org/10.1016/j.jpba.2020.113637.

6. Ochiai, C.; Katagiri, Y.; Kobayashi, S.; Naitoh, I.; Yoneyama, S.; Tomita, K.; Dongze, L.; Hikono, H.; Murakami, K. Development of a microchip electrophoresis-based, high-throughput PCR-RFLP method to type Tax 233 variants of bovine leukemia virus in Japan. Archives of Virology 2020, 165, 2961-2966, https://doi.org/10.1007/s00705-020-04842-w.

7. Andoh, K.; Kimura, K.; Nishimori, A.; Hatama, S. Development of an in situ hybridization assay using an AS1 probe for detection of bovine leukemia virus in BLV-induced lymphoma tissues. Archives of Virology 2020, 165, 2869-2876, https://doi.org/10.1007/s00705-020-04837-7.

8. Selim, A.; Manaa, E.A.; Alanazi, A.D.; Alyousif, M.S. Seroprevalence, risk factors and molecular identification of bovine leukemia virus in egyptian cattle. Animals 2021, 11, 1-9, https://doi.org/10.3390/ani11020319.

9. Kazemimanesh, M.; Madadgar, O.; Steinbach, F.; Choudhury, B.; Azadmanesh, K. Detection and molecular characterization of bovine leukemia virus in various regions of Iran. Journal of General Virology 2021, 100, 1315-1327, https://doi.org/10.1099/JGV.0.001303.

10. Epizootic situation in the Russian Federation in 2020. Available online: https://fsvps.gov.ru/fsvpsdocs/ru/iac/rf/2020/iac2020_4_quater.pdf [accessed on 03 June 2021].

11. Juliarena, M.A.; Barrios, C.N.; Ceriani, M.C.; Esteban, E.N. Hot topic: Bovine leukemia virus (BLV)infected cows with low proviral load are not a source of infection for BLV-free cattle. Journal of Dairy Science 2016, 99, 4586-4589, https://doi.org/10.3168/jds.2015-10480.

12. Durkin, K.; Rosewick, N.; Artesi, M.; Hahaut, V.; Griebel, P.; Arsic, N.; Burny, A.; Georges M.; van den Broeke, A. Characterization of novel Bovine Leukemia Virus (BLV) antisense transcripts by deep sequencing reveals constitutive expression in tumors and transcriptional interaction with viral microRNAs. Retrovirology 2016, 13, https://doi.org/10.1186/s12977-016-0267-8. 
13. Chen, Y.C.; Chang, C.C.; Hsu, W.L.; Chuang, S.T. Dairy cattle with bovine leukaemia virus RNA show significantly increased leukocyte counts. Veterinary journal (London, England : 1997) 2020, 257, 105449, https://doi.org/10.1016/j.tvj1.2020.105449.

14. Pluta, A.; Jaworski, J.P.; Douville, R.N. Regulation of expression and latency in BLV and HTLV. Viruses 2020, 12, 1079, https://doi.org/10.3390/v12101079.

15. Baltzell, K.A.; Shen, H.M.; Krishnamurthy, S.; Sison, J.D.; Nuovo, G.J.; Buehring, G.C. Bovine leukemia virus linked to breast cancer but not coinfection with human papillomavirus: Case-control study of women in Texas. Cancer 2018, 124, 1342-1349, https://doi.org/10.1002/cncr.31169.

16. Delarmelina, E.; Buzelin, M.A.; de Souza, B.S.; Souto F.M.; Bicalho J.M.; Falcao Camara R.J.; Resende C.F.; Bueno B.L.; Victor R.M.; Florentino Galinari G.C.; et al. High positivity values for bovine leukemia virus in human breast cancer cases from Minas Gerais, Brazil. PLoS One 2020, e239745, https://doi.org/10.1371/journal.pone.0239745.

17. Buehring, G.C.; Shen, H.; Schwartz, D.A.; Lawson, J.S. Bovine leukemia virus linked to breast cancer in Australian women and identified before breast cancer development. PLoS One 2017, 12, e0179367, https://doi.org/10.1371/journal. pone.0179367.

18. Giovanna, M.; Carlos, U.J.; María, U.A.; Gutierrez, M.F. Bovine Leukemia Virus Gene Segment Detected in Human Breast Tissue. Open Journal of Medical Microbiology 2013, 03, 84-90, https://doi.org/10.4236/ojmm.2013.31013.

19. Martinez Cuesta, L.; Lendez, P.A.; Nieto Farias, M.V.; Dolcini, G.L.; Ceriani, M.C. Can Bovine Leukemia Virus Be Related to Human Breast Cancer? A Review of the Evidence. Journal of Mammary Gland Biology and Neoplasia 2018, 23, 101-107, https://doi.org/10.1007/s10911-018-9397-z.

20. Pravila po profilaktike $\mathrm{i}$ bor'be $\mathrm{s}$ lejkozom krupnogo rogatogo skota. Available online: http://ivo.garant.ru/\#/document/2157108/paragraph/92/doclist/31864/showentries/0/highlight/\%D0\%BB\%D 0\%B5\%D0\%B9\%D0\%BA\%D0\%BE\%D0\%B7:1 [accessed on 03 June 2021].

21. Saushkin, N.Yu.; Samsonovaa, J.V.; Osipova, A.P.; Kondakova, S.E.; Khammadov, N.I.; Usoltsev, K.V.; Makaev, Kh.Z.; Chernov A.N. Comparison of PCR and ELISA Methods for the Detection of Bovine Leucosis in Dried Blood Spots. Moscow University Chemistry Bulletin 2016, 71, 319-323, https://doi.org/10.3103/S0027131416050084.

22. Brandon, R.B.; Naif, H.; Daniel, R.C.; Lavin, M.F. Early detection of bovine leukosis virus DNA in infected sheep using the polymerase chain reaction. Research in Veterinary Science 1991, 50, 89-94, https://doi.org/10.1016/0034-5288(91)90059-w.

23. Murtaugh, M.P.; Lin, G.F.; Haggard, D.L.; Weber, A.F.; Meiske, J.C. Detection of bovine leukemia virus in cattle by the polymerase chain reaction. Journal of Virological Methods 1991, 33, 73-85, https://doi.org/10.1016/0166-0934(91)90009-O.

24. Rola, M.; Kuzmak, J. The detection of bovine leukemia virus proviral DNA by PCR-ELISA. Journal of Virological Methods 2002, 99, 33-40, https://doi.org/10.1016/s0166-0934(01)00384-6.

25. Jaworski, J.P.; Pluta, A.; Rola-Łuszczak, M.; McGowan, S.L.; Finnegan, C.; Heenemann, K.; Carignano, H.A.; Alvarez , I.; Murakami, K.; Willems, L.; et al. Interlaboratory Comparison of Six Real-Time PCR Assays for Detection of Bovine Leukemia Virus Proviral DNA. Journal of Clinical Microbiology 2018, 56, e00304-18, https://doi.org/10.1128\%2FJCM.00304-18.

26. Mayuko Jimba; Shin-nosuke Takeshima; Kazuhiro Matoba; Daiji Endoh; Yoko Aida. BLV-CoCoMo-qPCR: Quantitation of bovine leukemia virus proviral load using the CoCoMo algorithm. Retrovirology 2010, 7, 91, https://doi.org/10.1186/1742-4690-7-91.

27. Pluta, A.; Blazhko, N.V.; Ngirande, C.; Joris, T.; Willems, L.; Kuźmak, J. Analysis of nucleotide sequence of tax, mirna and ltr of bovine leukemia virus in cattle with different levels of persistent lymphocytosis in Russia. Pathogens 2021, 10, 1-21, https://doi.org/10.3390/pathogens10020246.

28. Pluta, A.; Willems, L.; Douville, R.N.; Kuźmak, J. Effects of naturally occurring mutations in bovine leukemia virus $5^{\prime}$-ltr and tax gene on viral transcriptional activity. Pathogens 2020, 9, 1-28, https://doi.org/10.3390/pathogens9100836.

29. Khammadov, N.I. Genetic markers of the cattle foot and mouth disease virus: Genomic analysis. Problemy Osobo Opasnykh Infektsii 2019, 2, 111-116, https://doi.org/10.21055/0370-1069-2019-2-111-116.

30. Beier, D., Blankenstein, P., Marquardt, O., Kuzmak, J. Identification of different BLV provirus isolates by PCR, RFLPA and DNA sequencing. Berl Munch Tierarztl Wochenschr. Jul-Aug 2001; 114, 252-6.

31. Sagata, N.; Yasunaga, T.; Tsuzuku-Kawamura J.; Ohishi K.; Ogawa Y.; Ikawa, Y. Complete nucleotide sequence of the genome of bovine leukemia virus: its evolutionary relationship to other retroviruses. 
Proceedings of the National Academy of Sciences of the United States of America 1985, 82, 677-681, https://doi.org/10.1073/pnas.82.3.677.

32. Safina, R.F. DNA markers encoding the proteins LTR, p24, gp51, pol to indicate the causative agent of bovine leukemia in PCR-RT. Scientific Notes Kazan Bauman State Academy of Veterinary Medicine 2020, 242, 153 158, https://doi.org/10.31588/2413-4201-1883-242-2-153-158.

33. Dube, S.; Dolcini, G.; Abbott, L.; Mehta, S.; Dube, D.; Gutierrez, S.; Ceriani, C.; Esteban, E.; Ferrer, J.; Poiesz, B. The complete genomic sequence of a BLV strain from a Holstein cow from Argentina. Virology 2000, 277, 379-386, https://doi.org/10.1006/viro.2000.0622.

34. Andoh, K.; Nishimori, A.; Sakumoto, R.; Hayashi, K.; Hatama, S. The chemokines CCL2 and CXCL10 produced by bovine endometrial epithelial cells induce migration of bovine B lymphocytes, contributing to transuterine transmission of BLV infection. Veterinary Microbiology 2020, 242, 108598, https://doi.org/10.1016/j.vetmic.2020.108598.

35. Derse, D.; Diniak, A.J.; Casey, J.W.; Deininger, P.L. Nucleotide sequence and structure of integrated bovine leukemia virus long terminal repeats. Virology 1985, 141, 162-166, https://doi.org/10.1016/00426822(85)90193-x.

36. Murakami, H.; Uchiyama, J.; Suzuki, C.; Nikaido, S.; Shibuya, K.; Sato, R.; Maeda, Y.; Tomioka, M.; Takeshima, S.N.; Kato, H.; et al. Variations in the viral genome and biological properties of bovine leukemia virus wild-type strains. Virus Research 2018, 253, 103-111, https://doi.org/10.1016/j.virusres.2018.06.005.

37. Yu, C.; Wang, X.; Zhou, Y.; Wang, Y.; Zhang, X.; Zheng, Y. Genotyping bovine leukemia virus in dairy cattle of Heilongjiang, northeastern China. BMC Veterinary Research 2019, 15, 179, https://doi.org/10.1186/s12917-019-1863-3.

38. Dao, T.D.; Bui, V.N.; Omatsu, T.; Katayama, Y.; Mizutani, T.; Ogawa, H.; Imai, K. Application of the SureSelect target enrichment system for next-generation sequencing to obtain the complete genome sequence of bovine leukemia virus. Archives of Virology 2018, 163, 3155-3159, https://doi.org/10.1007/s00705-0183957-9.

39. Polat, M.; Takeshima, S.N.; Hosomichi, K.; Kim, J.; Miyasaka, T.; Yamada, K.; Arainga, M.; Murakami, T.; Matsumoto, Y.; de la Barra Diaz,V.; et al. A new genotype of bovine leukemia virus in South America identified by NGS-based whole genome sequencing and molecular evolutionary genetic analysis. Retrovirology 2016, 13, 4, https://doi.org/10.1186/s12977-016-0239-z.

40. Polat, M.; Moe, H.H.; Shimogiri, T.; Moe, K.K.; Takeshima, S.N.; Aida,Y. The molecular epidemiological study of bovine leukemia virus infection in Myanmar cattle. Archives of Virology 2017, 162, 425-437, https://doi.org/10.1007/s00705-016-3118-y.

41. Dube, S.; Abbott, L.; Dube, D.K.; Dolcini, G.; Gutierrez, S.; Ceriani, C.; Juliarena, M.; Ferrer, J.; Perzova, R.; Poiesz, B.J. The complete genomic sequence of an in vivo low replicating BLV strain. Virology Journal 2009, 6, 120, https://doi.org/10.1186/1743-422x-6-120.

42. Wang, M.; Wang, Y.; Baloch, A.R.; Pan, Y.; Xu, F.; Tian, L.; Zeng, Q. Molecular epidemiology and characterization of bovine leukemia virus in domestic yaks (Bos grunniens) on the Qinghai-Tibet Plateau, China. Archives of Virology 2018, 163, 659-670, https://doi.org/10.1007/s00705-017-3658-9.

43. Juliarena, M.A.; Barrios, C.N.; Lützelschwab, C.M.; Esteban, E.N.; Gutiérrez, S.E. Bovine leukemia virus: Current perspectives. Virus Adaptation and Treatment 2017, 9, 13-26, https://doi.org/10.2147/VAAT.S113947.

44. Takeshima, S.N.; Kitamura-Muramatsu, Y.; Yuan, Y.; Polat, M.; Saito, S.; Aida, Y. BLV-CoCoMo-qPCR2: improvements to the BLV-CoCoMo-qPCR assay for bovine leukemia virus by reducing primer degeneracy and constructing an optimal standard curve. Archives of Virology 2015, 160, 1325-1332, https://doi.org/10.1007/s00705-015-2377-3. 